\title{
Trainer Filter Sinyal High Pass Filter Sebagai Media Pembelajaran Mahasiswa Teknik Elektro
}

\author{
Yussi Anggraini $^{*}$ dan Irna Tri Yuniahastuti $^{1}$ \\ ${ }^{1}$ Jurusan Teknik Elektro, Fakultas Teknik, Universitas PGRI Madiun \\ *Corresponding author, e-mail: yussi@unipma.ac.id
}

\begin{abstract}
Abstrak - Pemakaian alat bantu dalam proses belajar mengajar sangat memberikan kemudahan ketika proses pembelajaran. Pengembangan media belajar trainer high pass filter menjadi tujuan utama dari penelitian ini. Rancangan pada penelitian menggunakan metode pengembangan (research and development). Langkah yang dilakukan dalam Pengembangan high pass filter trainer ini adalah dengan menggunakan model ADDIE. Yang menjadi subyek di penelitian ini ialah peserta didik program studi Teknik elektro sebanyak 22 orang. Data diperoleh dari hasil kuesioner dan dokumentasi menggunakan analisis deskriptif. Berdasarkan analisa data diperoleh hasil bahwa penggunaan media HPF mampu meningkatkan proses pembelajaran rangkaian digital. Hasil validasi isi oleh ahli materi memperoleh tingkat validasi dengan persentase sebesar $\mathbf{8 4 , 3 \%}$ dengan kategori sangat layak. Validasi konstruk dengan ahli media pembelajaran sebesar $\mathbf{7 9 , 6 \%}$ dan validasi terhadap uji terhadap mahasiswa sebesar $92,6 \%$ dengan kategori sangat layak. Maka dari itu dapat ditari kesimpulan bahwa media pembelajaran trainer HPF layak diterapkan pada pembelajaran praktikum teknik elektro untuk membantu kelancaran proses pembelajaran.
\end{abstract}

Kata kunci : high pass filter, Rangkaian Digital, Media Pembelajaran

\begin{abstract}
Use of tools in teaching and learning process is very convenient when the learning process. The development of learning media of high pass filter trainers became the main objective of this research. The design of the research uses research and development methods. The steps taken in developing this high pass filter trainer are by using the ADDIE model. The subjects in this study were 22 students of the Electrical Engineering study program. Data obtained from the results of questionnaires and documentation using descriptive analysis. Based on data analysis, it was found that the use of HPF media was able to improve the learning process of digital circuits. The content validation results by the material expert obtained a validation rate of $84.3 \%$ with a very decent category. The validation of the constructs with the learning media experts was 79.6\% and the validation of the test against the students was $92.6 \%$ with very decent category. Therefore it can be concluded that the HPF trainer learning media is feasible to be applied to the practical learning of electrical engineering to help smooth the learning process.
\end{abstract}

Keywords: high pass filter, Digital Circuit, Learning Media

This is an open access article distributed under the Creative Commons 4.0 Attribution License, which permits unrestricted use, distribution, and reproduction in any medium, provided the original work is properly cited. C2018 by Author and Universitas Negeri Padang

\section{Pendahuluan}

Penelitian ini berkaitan dengan permasalahan proses pembelajaran yang harus ditingkatkan. Berdasarkan hal itu dapat terlihat dari aktivitas mahasiswa yang cenderung pasif apabila melaksanakan praktikum tanpa mengggunakan trainer dan kelengkapan perangkat pembelajarnnya. Belum adanya media trainer HPF pada matakuliah tersebut. Kemudahan pembelajaran di dalam sebuah kelas tidak akan lepas dari penggunaan media pembelajaran baik berupa buku, trainer, jobsheet dan lain-lain. Penelitian ini bertujuan untuk mengembangkan trainer media pembelajaran pada matakuliah rangkaian digital dengan jobshet untuk mahasiswa dan jobsheet dosen sebagai pegangan untuk mempermudah proses pembelajaran. Langkah yang dilakukan untuk mencapai target tersebut ialah membuat alat berupa trainer high pass filter orde 1, mengembangkan buku pegangan, mengkaji hasil dari penerapan media tersebut apakah memberikan dampak positif terhadap mahasiswa. Model yang digunakan ADDIE untuk menganalisis proses pengembangan yang telah dilakukan. 
Pendidikan di indonesia saat ini lebih dikenal dengan teacher center sekarang sudah berubah menjadi student center untuk meningkatkan pendidikan yang ada agar lebih baik. Difokuskan pada siswa untuk lebih aktif agar lebih menunjang proses pembelajaran menjadi lebih efektif dan aktif. Para pengajar harus lebih memahami kondisi peserta didik agar dapat menerapkan metode dan model mengajar yang tepat. seperti yang dikemukakan [1] profesionalitas pendidik untuk melakukan pembelajaran akan ssngat mempengaruhi hasil belajar siswa dilihat dari persiapan awal mengajar, metode mengajar, dan media pembelajaran yang telah digunakan. Oleh karena itu pembelajaran efektif dan interaktif mampu memberikan solusi atas permasalahan itu. Media belajar interkatif mampu memebrikan visualisasi langsung terhadap peserta didik sehingga mampu berinteraksi langsung dengan siswa [2].

\section{StUdi PUSTAKa}

Prestasi yang dihasilkan oleh seorang peserta didik memperoleh pengaruh dari macam-macam faktor dari luar maupun dalam peserta didik [3]. Salah satunya yang mampu memberikan pengaruh pada sebuah pembelajaran yaitu media pembelajaran. Pengaruh yang diberikan sangat signifikan sekali terhadap mahasiswa [4]. Di antaranya adalah memberikan dampak terhadap motivasi belajar, mahasiswa akan lebih tertarik terhadap proses pembelajaran apabila proses itu memberikan kenyamanan dan memberikan sebuah inovasi di dalamnya [5]. Jika proses pembelajarn lancar dan memberikan semangat kepada mahasiswa untuk belajar secara otomatis akan meningkatkan hasil belajar mahasiswa dikarenakan setiap proses pembelajaran tidak akan lepas dari media pembelajaran.

Pembelajaran rangkaian digital sekarang masih menggunakan metode konvensional. Penyampaian materi khususnya praktikum tentang High Pass Filter belum menggunakan media trainer. Trainer adalah alat bantu peraga yang membantu pengajar dalam meningkatkan keterampilan dan pengetahuan peserta didik [6]. Inovasi yang akan dilakukan pendidik untuk menunjang pembelajaran salah satunya adalah membuat sebuah media belajar untuk kegiatan praktikum mahasiswa. Menurut Midun dalam [6], media pembelajaran merupakan sebagian teknologi yang mampu memecahkan permasalahan dalam pembelajaran.

Trainer HPF digunakan pada matakuliah rangkaian digital yang akan disusun untuk dijadikan alat bantu pembelajaran praktikum. Kategori media pembelajaran ini berfungsi dengan baik jika hasil dari praktikum mampu meloloskan frekuensi tinggi sesuai dengan pendapat [7] bahwa HPF adalah sebuah filter sinyal yang meloloskan frekuensi tegangan tinggi. Fungsi dari penggunaan trainer ini adalah untuk memudahkan pemahaman, menganalisis persoalan terkait materi tersebut serta mengaktifkan mahasiswa ketika pembelajaran praktikum. Penunjang sebuah media pembelajaran adalah perangkat pembelajaran baik itu handout, modul,jobsheet dan lain-lain. Dalam proses pembelajaran praktikum belum dilengkapi dengan perangkat pembelajaran sehingga mahasiswa masih kurang memahami ketika pembelajaran berlangsung.

Beberapa hal yang ingin dicapai diantaranya adalah membuat sebuah trainer pembelajaran yang diharapkan dengan media pembelajaran ini mahasiswa yang sedang praktikum dapat lebih mengerti fungsi dan cara kerja dari filter lolos atas. Pada trainer ini akan dilengkapi dengan jobsheet dosen dan jobsheet mahasiswa. Dengan menggunakan sebuah media belajar yang inovatif dan efektif diharapkan HPF Trainer mampu digunakan sebagai salah satu alternatif media pembelajaran praktikum sehingga mampu memudahkan mahasiswa dalam belajar memahami dan menganalisis terkait materi high pass filter. Berdasarkan latar belakang tersebut maka artikel ini mempelajari tentang "Trainer Filter Sinyal High Pass Filter Sebagai Media Pembelajaran Mahasiswa Teknik Elektro"

\section{METODE}

Metode penelitian yang digunakan dalam penelitian ini menggunakan rancangan penelitian pengembangan/ R\&D (Research and Development). Pengembangan high pass filter pada matakuliah rangkaian digital mahasiswa teknik elektro menggunakan model pengembangan ADDIE. Model pengembangan ini terdiri dari lima langkah yaitu: (1) analisis (analyze), (2) desain (design)(3) pengembangan (development) (4) implementasi (implement), dan (5) evaluasi (evaluate). Pemilihan model pengembangan ADDIE ini karena pada model pengembangan tersebut terdapat evaluasi pada setiap langkah pengembangannya, sehingga diharapkan dapat menghasilkan produk yang mempunyai nilai validitas yang tinggi. Model pengembangan ADDIE dapat dilihat pada Gambar 1. 


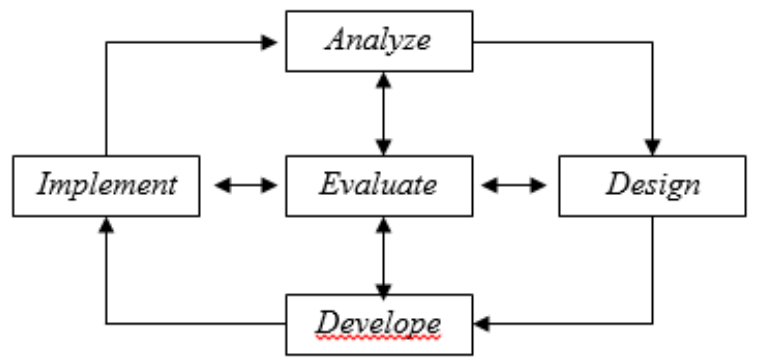

Gambar 1. Model Pengembangan ADDIE

Dalam penelitian ini menggunakan subyek penelitian dari mahasiswa teknik elektro sebanyak 22 mahasiswa. Instrumen pengambilan data menggunakan angket dan dokumentasi. Instrumen penggunaan angket berguna untuk mengetahui tentang isi dari media tersebut apakah relatif mudah dipahami atau tidak. Teknik analisis data yang dilakukan menggunakan lualitatif dan kuantitatif. Data kualitatif berupa pemaparan hasil produk media pembelajaran dan selanjutnya menggunakan data kuantitatif yakni memaparkan tentang kelayakan produk trainer media pembelajaran dengan memakai skala likert dengan bobot pengukuran dari 4,3,2,1 dan tabel kelayakan trainer HPF dapat dilihat pada Tabel 1.

Tabel 1. Penilaian Kelayakan Trainer HPF

\begin{tabular}{|c|c|l|}
\hline No & Skla penilaian (\%) & Keterangan \\
\hline 1. & $0 \%-25 \%$ & Sangat tidak layak \\
\hline 2. & $25 \%-50 \%$ & Kurang layak \\
\hline 3. & $50 \%-75 \%$ & Cukup layak \\
\hline 4. & $75 \%-100$ & Sangat layak \\
\hline
\end{tabular}

\section{HASIL DAN PEMBAHASAN}

Pengolahan data dalam penelitian ini meliputi (1) analisis uji validitas isi oleh ahli materi, (2) analisis uji validitas konstruk oleh ahli media, (3) uji coba terhadap mahasiswa. Analisis hasil uji validasi isi oleh ahli materi disajikan pada tabel 2 dan grafik 1 .

Tahapan pada uji validasi pada penelitian ini terdiri dari uji validasi ahli materi pada jobsheet, uji validasi ahli media trainer HPF dan uji coba terhadap mahasiswa. Ahli materi disini yang digunakan adalah dosen dari pendidikan teknik elektro universitas PGRI Madiun dan ahli validasi media trainer adalah dosen Teknik elektro Universitas PGRI Madiun. Sebelum melakukan uji validasi terlebih dahulu yang dilakukan adalah demo media trainer HPF, bahan ajar dikonsultasikan hingga dianggap layak untuk dilakukan uji coba. Uji coba dilakukan terhadap mahasiswa teknik elektro sejumlah 22 anak. Hasil uji validasi ini berupa angket sebagai alat ukur terhadap media trainer ini.
Tabel 2 .Hasil uji validasi isi

\begin{tabular}{|l|l|l|l|l|l|}
\hline No & Kategori & Rerata & Hasil & Skor & $\%$-tase \\
\hline 1. & Isi dan tujuan & 3,5 & 31 & 36 & $86,1 \%$ \\
\hline 2. & Proses & 3,3 & 16,5 & 20 & $82,5 \%$ \\
\hline & Persentase rata-rata & & $84,3 \%$ \\
\hline
\end{tabular}

Dari penyajian Tabel 2 menjelaskan hasil uji validasi oleh ahli materi dengan bobot nilai $84,3 \%$. Aspek penilaian yang dilakukan yaitu kualitas isi dan kualitas pembelajaran. Kategori hasil validasi isi menunjukkan sangat layak sehingga baik untuk diterapkan pada proses pembelajaran. Hasil uji validasi isi ini disajikan dalam bentuk Grafik 1 .

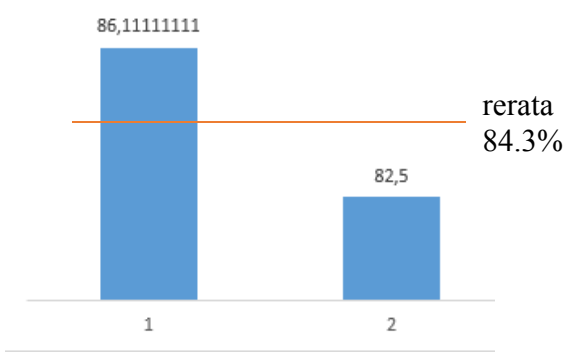

Grafik 1. Hasil validasi ahli materi

Selanjutnya proses analisis yang dilakukan adalah validasi terhadap media pembelajaran pada ahli media yang dapat dilihat pada Tabel 3 dan Grafik 2.

Tabel 3. Hasil uji validasi ahli media

\begin{tabular}{|l|l|l|l|l|l|}
\hline No & Kategori & Rerata & Hasil & Skor & $\%$-tase \\
\hline 1. & Keteknisan & 3,3 & 27 & 32 & $84,3 \%$ \\
\hline 2. & Kemanfaatan & 3,4 & 9 & 12 & $75,0 \%$ \\
\hline \multicolumn{6}{|l|}{ Persentase rata-rata } \\
\hline
\end{tabular}

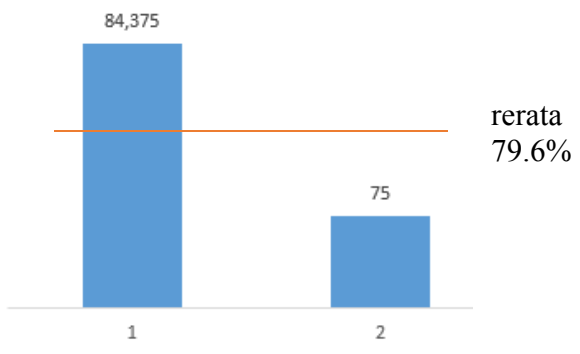

Grafik 2. Hasil validasi ahli media

Tabel 3 menunjukkan bahwa hasil dari uji validasi ahli media sangat layak digunakan dilihat ari persentase rata-rata sebesar 79,6\%. Aspek penilaian yang dilakukan ada kualitas teknik dan kemanfaatan media pembelajaran yang dinilai oleh ahli media yang ada di universitas. Selain penilaian 
ahli materi dan ahli media, media pembelajaran ini juga dilakukan uji coba terhadap mahasiswa yang dapat dilihat pada Tabel 4 dan Grafik 3.

Tabel 4. Hasil uji coba Mahasiswa

\begin{tabular}{|l|l|l|l|l|}
\hline No & Kategori & $\begin{array}{l}\text { Jumlah } \\
\text { Hasil }\end{array}$ & $\begin{array}{l}\text { Jumlah } \\
\text { Maksimal }\end{array}$ & $\begin{array}{l}\text { Persen } \\
(\%)\end{array}$ \\
\hline 1. & Isi dan tujuan & 323 & 352 & $91,7 \%$ \\
\hline 2. & $\begin{array}{l}\text { Proses } \\
\text { pembelajaran }\end{array}$ & 238 & 264 & $90,2 \%$ \\
\hline 3. & Keteknisan & 675 & 704 & $95,8 \%$ \\
\hline 4. & Manfaat & 231 & 264 & $87,5 \%$ \\
\hline 5. & Jumlah & 1467 & 1584 & $92,6 \%$ \\
\hline
\end{tabular}

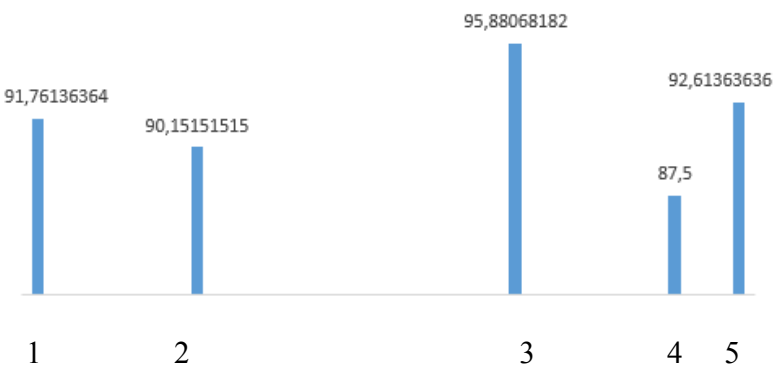

Grafik 3. Hasil uji coba mahasiswa

Berdasarkan Tabel 4 dan Grafik 3 menunjukkan hasil uji validasi kepada mahasiswa teknik elektro dengan nilai persentase sebesar 92,6\% dengan kategori sangat layak digunakan. Uji coba responden ini dilakukan untuk mengetahui tanggapan mahasiswa terhadap media pembelajaran praktikum yang digunakan.

Berdasarkan hasil analisa data yang telah dilakukan diketahui bahwa media pembelajaran high pass filter layak digunakan pada proses pembelajarn praktek rangkaian digital. Pengujian media dilakukan terhadap ahli materi dan ahli media berguna untuk melihat kesesuaian media pembelajaran dengan relevansi materi [8]. Kisi-kisi instrumen yang digunakan untuk menilai materi tersebut antara lain kualitas isi dan tujuan serta kualitas pembelajaran. Menurut [9] menyatakan bahwa kualitas untuk menilai media pembelajaran terdiri dari kualitas isi dan tujuan, kualitas instruksional,dan kualitas teknis. Hasil penilaian validator menyatakan bahwa media pembelajaran HPF sangat layak digunakan. Adapun trainer yang digunakan seperti terlihat pada Gambar 2.

Tujuan dilakukannya penelitian ini memperoleh informasi serta gambaran dan masukan tentang media yang selama ini dipakai dalam proses pembelajaran sehari - hari, sehingga dapat diketahui media yang ocok dan tepat untuk digunakan dalam proses praktikum khususnya pada mata kuliah rangkaian digital UNIPMA. Adapun langkah yang digunakan untuk merancang trainer itu menggunakan ADDIE. Menurut [8] model pengembangan ADDIE terdiri dari 5 tahap pengembangan, yaitu: Analyze, Design, Development, Implementation dan, Evaluation. Adapun langkah yang dilakukan untuk mendapatkan data adalah dengan wawancara terbuka untuk mendapatkan data keterangan awal tentang proses pembelajaran praktikum yang selama ini berlangsung.

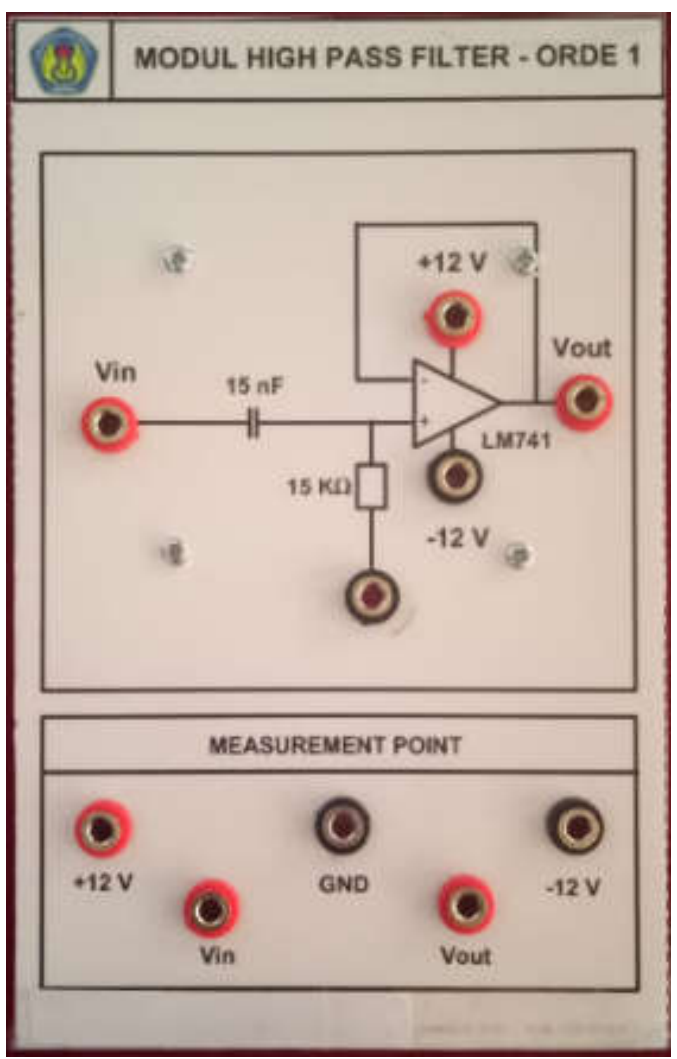

Gambar 2. Trainer filter sinyal HPF

Media yang dikembangkan oleh peneliti ini berupa pengembangan media belajar filter sinyal pada rangkaian digital. Filter sinyal terdiri dari beberapa yakni low pass filter, high pass filter dan band stop filter. Penggunaan filter sinyal high pass tidak hanya bisa digunakan untuk trainer pembelajaran namun dapat diaplikasikan terhadap peralatan elektronik lainnya [10]. Fungsi dari penggunaan trainer ini adalah untuk memudahkan pemahaman, menganalisis persoalan terkait materi tersebut serta mengaktifkan mahasiswa ketika pembelajaran praktikum.

Media pembelajaran yang baik adalah yang memiliki efektivitas tinggi terhadap penggunanya. Seperti pada penelitian [11] mengatakan bahwa media pembelajarn mandiri akan dijadikan sebagai pelengkap pembelajaran tatap muka didalam 
sebuah proses pembelajaran untuk meningkatkan motivasi dan kesadaran akan belajar kepada mahasiswa. Dalam memilih media pembelajaran terdapat aspek-aspek yang perlu dipertimbangkan, diantaranya, apa tujuan pembelajaran yang akan dicapai, dan materi apa yang akan disampaikan pada siswa, dilihat dari segi hasil belajar siswa pada penilaian pengetahuan, maka trainer ini sudah dapat digunakan sebagai media dan sumber belajar bagi peserta didik [12].

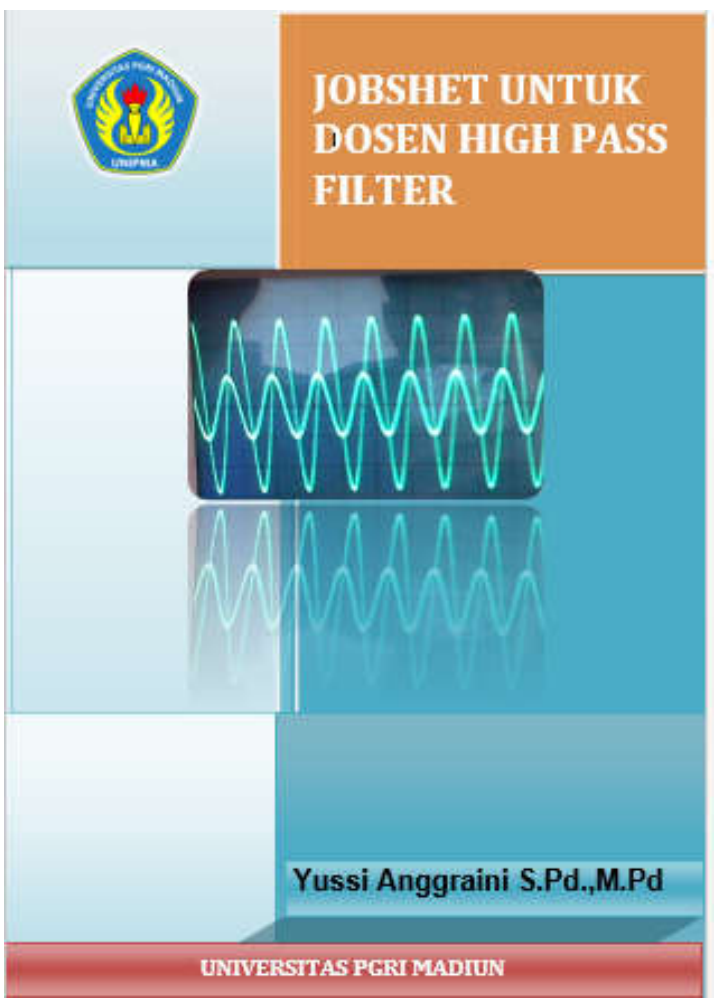

Gambar 3. Cover Jobsheet Dosen

Berdasarkan hasil pengujian yang telah dilaksanakan pada kegiatan praktikum penggunaan trainer memberikan hasil bahwa kualitas teknis menghasilkan tanggapan yang baik/layak untuk digunakan dari responden. Dilihat dari kerapian alat yang dirancang, tampilan yang mengesankan, komposisi warna yang tidak mengganggu, dan yang terpenting adalah mempermudah proses pembelajaran praktikum. Dilihat dari segi manfaat media pembelajaran ini memberikan banyak manfaat terutama untuk mahasiswa yaitu mempermudah kegiatan praktikum dengan praktis dan dilengkapi dengan jobsheet mahasiswa dan dosen yang dapat dilihat pada Gambar 3 dan Gambar 4. Berbagai penelitian juga mengatakan tentang pengembangan media pembelajaran mampu meningkatkan keefektifan pembelajaran pada berbagai matakuliah [13].

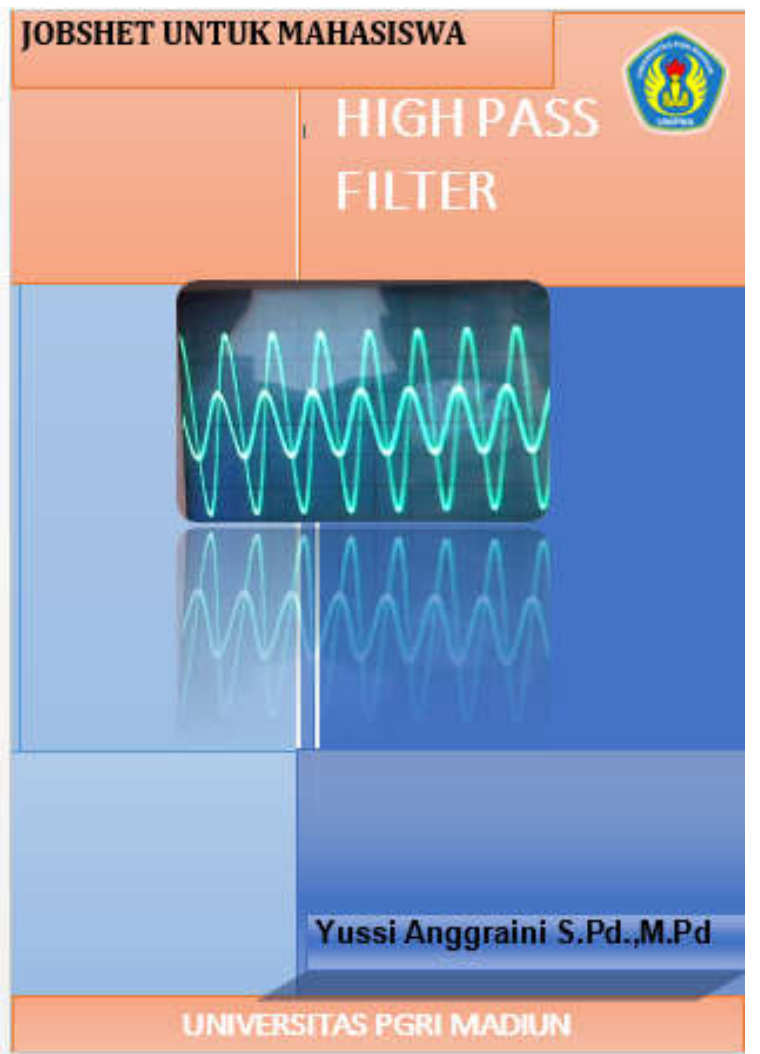

Gambar 4. Cover Jobsheet Mahasiswa

\section{KESIMPULAN}

Berdasarkan hasil analisis data dan pembahasan maka dapat disimpulakan bahwa (1) trainer media pembelajaran high pass filter yang telah dikembangkan layak untuk digunakan sebagai media pembelajaran praktikum rangkaian digital untuk mahasiswa teknik elektro dengan hasil validasi rata-rata 92,6\%. (2) hasil validasi terhadap ahli materi memiliki kategori layak digunakan dengan persentase $84,3 \%$, (3) sedangkan Tingkat kelayakan penggunaan media pembelajaran high pass filter orde 1 dilihat dari validasi ahli media memperoleh persentase sebesar $79,6 \%$ sehingga dapat disimpulkan bahwa media belajar HPF orde 1 sangat layak untuk diterapkan kepada mahasiswa.

\section{DAFTAR PUSTAKa}

[1] Darwin. (2018). Pengembangan training kits pengukuran listrik sebagai media pembelajaran pada mata pelajaran memahami pengukuran komponen elektronika di SMK Muhamadiyah 1 padang. INVOTEK. 18.(1)

[2] Muliyana, Habibullah, \& Dwiparma. (2017). Pengembangan multimedia interaktif pada mata pelajaran dasar dan pengukuran listrik. 
Jurnal Inovasi Vokasional dan

Teknologi.17.(2).

[3] Rayandra Asyhar. (2012). Kreatif Mengembangkan Media Pembelajaran. Jakarta: Refrensi Jakarta.

[4] Slameto.(2010). Belajar dan Faktor-faktor yang Mempengaruhinya. Jakarta: PT Rineka Cipta.

[5] Branch,R.M. (2009). Instructional design: The ADDIE approach. 722: Springer Science \& Business Media

[6] Sugiyono. (2011). Metode Penelitian Kuantitatif Kualitatif \& RND. Bandung : Alfabeta

[7] Yussi A \& Ina S. (2018). Pengembangan Media Pembelajaran Pengukuran Listrik berbasis Augmented Reality Pada Mahasiswa Teknik Elektro UNIPMA. Jurnal Pendidikan Teknik Elektro. 3(1).37-41

[7] Ibrahim, Muslimin.)2010). Dasar-Dasar Proses Belajar Mengajar Surabaya. Unesa University Press.

[8] Fitrilina1, Heru Dibyo Laksono1, Riko Derwin. (2016). Implementasi Filter High Pass Butterworth Pada Tensimeter Digital Menggunakan Arduino Mega2560 dan Smartphone Android Amplifier.6.(2).

[9] Asyhar, R.(2011). Kreatif Mengebangkan Media Pendidikan: Jakarta: Gaung Persada Press.

[10]Murinto.E,W.Risnadi,S.(2007). $\quad$ Analisis Perbandingan Metode Intensity Filtering Dengan Metode Frequency Filtering Sebagai Reduksi. Noise Pada Citra Digital. Seminar Nasional Aplikasi Teknologi Informasi 2007 (SNATI 2007). Yogyakarta. ISSN : 19075022.

[11] Andrizal. (2017). Pengembangan Media Pembelejaran Interaktif pada sistem e-learning universitas negeri padang. INVOTEK. 17.(2).

[12] Dabutar,Jelarwin. (2007). Pengaruh Media Pembelajaran Terhadap Hasil Belajar Pengelasan pada Siswa yang Berprestasi Tinggi dan Rendah di SMK Swasta 1 Trisakti Laguboti -Kabupaten Toba Samosir. Digital Library Universitas Negeri Malang

[13] Rifdarmon. (2018). Pengembangan Simulator Engine Trainer Integrated Active Wiring Diagram untuk meningkatkan efektifitas pembelajaran mata kuliah listrik dan elektronika otomotif. 18.(1).

\section{BiodataPenulis}

Yussi Anggraini lahir di Bojonegoro 3 Januari 1994. Sarjana pendidikan teknik elektro dari Universitas Negeri Malang lulus pada tahun 2015. Tahun 2017 memperoleh gelar magister pendidikan kejuruan teknik elektro di Universitas Negeri Malang. Menjadi staf pengajar di UNIPMA-Sekarang.

Irna Tri Yuniahastuti, lahir di Madiun 15 Juli 1991. Sarjana pendidikan teknik elektro dari Universitas Negeri Surabaya pada tahun 2013. Mendapat gelar magister teknik elektro tahun 2016 dari Intstitut Teknologi Surabaya. Menjadi staf pengajar teknik elektro di UNIPMA-Sekarang. 